\title{
Un record de Josep Romeu, editor
}

Josep Romeu i Figueras, nascut a Òdena el 1917, va morir el 18 de desembre de 2004, just al principi de les antigues libertates decembris i a tocar del triduum nadalenc que coneixia tan bé. Potser hauria somrigut escoltant un darrer sermó del bisbetó. Ja feia molts anys que s'havia jubilat i havia deixat de ser una figura singular a la Universitat Autònoma de Barcelona. M'agradaria deixar un retrat d'aquella presència, un esbós impressionista —els records llunyans sempre ho són, i els d'un estudiant encara més.

Apareixia a classe de tercer curs, tot dret sobre la poca estatura, amb la finalitat d'explicar literatura catalana medieval a uns estudiants que no sabíem, com aquell qui diu, que n'existís la noció: a l'antic batxillerat podíem haver llegit versos de Verdaguer o Maragall, podíem haver descobert Carner o podíem haver collit llibres recents, de Gabriel Ferrater o Joan Vinyoli, però Bernat Metge era encara un misteri. Seia a la taula del professor sense gaires pretensions, la pipa penjada, i anava desgranant la seva particular glossa de la Història de Martí de Riquer. Admirava la seva habilitat a canviar la pipa d'un costat a l'altre, la parsimònia. Recordo alguns detalls de l'explicació: ara un esquema de versificació pacientment copiat a la pissarra — la forma d'un rondell, posem per cas-, ara un comentari irònic sobre l'edat en què Ramon Llull va tenir la cèlebre visió de Crist crucificat, amb la bibliografia adequada. Transmetia gust literari: Llull en primer Iloc, en efecte, però sobretot la vida, les novelles, la poesia; Metge també, amb accent en l'escepticisme; i el Tirant i els tripijocs sentimentals. Sobre el Tirant, examinava: en dues hores havíem de sintetitzar el saber de Riquer sobre la cavalleria i les fonts, i de propina comentar un episodi de la novella. De Lo somni, en canvi, en volia un treball amb l'es- tat de la qüestió i una lectura detallada del diàleg amb opinió pròpia.

A segon cicle aquesta metodologia escolar canviava tot d'un plegat. Per al curs de poesia popular — una espècie gairebé extingida — reclamava treballs de camp, ombres més que reflexos de la feina que ell mateix havia fet sobre la transmissió de la llegenda del Comte Arnau o la de la contalla del Drac de Coll de Canes, la que separa El Ripollès de La Garrotxa i té records del mite de Perseu i la Medusa. Per al curs de narrativa en vers, podia exigir la consulta en manuscrit de textos llavors encara inèdits en edició crítica (cas de La faula de Guillem de Torroella o del Fraire de Joi) o estudis d'obres poc conegudes (el Salut d'amor o el Frondino e Brisona). Aquestes feines es presentaven a classe i, encara que avui farien avergonyir, tinc la impressió que la pedagogia creava adeptes. Josep Romeu tenia el costum —un costum de senyor de comentar els resultats d'aquests treballs a casa seva al carrer París, com si fossin tutorials al despatx d'un college britànic. Amb el mateix esperit, que no sé pas d'on havia sortit, feia un curs d'edició de textos, val a dir de transcripció de textos medievals - la transcription class de Malcolm Parkes a Oxford no era gaire diferent: el professor transcriu i ensenya algun secret; l'alumne imita mentre fa els deures al pupitre.

A la Facultat corria la veu que el professor Alberto Blecua recomanava les classes del Dr. Romeu: «es muy buen editor», deia amb poder de convicció. Ho devia dir, sobretot, pels dos magnífics volums del Cancionero musical de Palacio. Abans d'ingressar a l'Autònoma, Josep Romeu ja era professor d'investigació al Consejo Superior de Investigaciones Científicas. Hi havia treballat amb el gran musicòleg Higini Anglès i per al Cancionero havia collaborat amb Antonio 


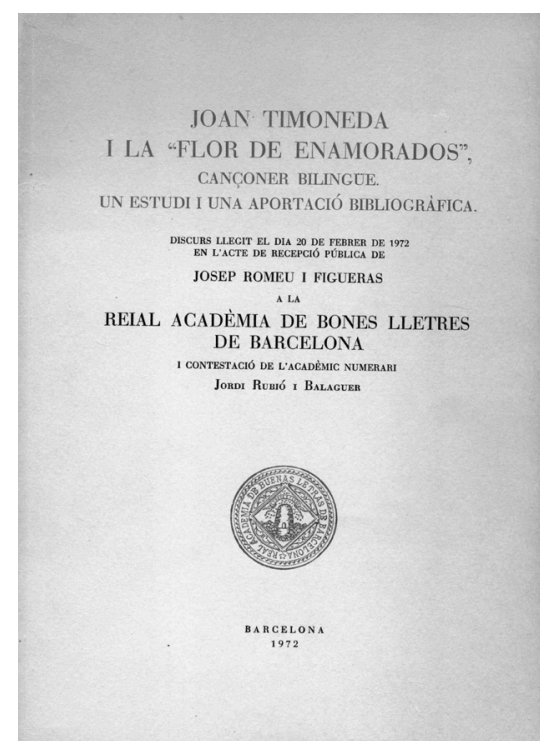

Rodríguez-Moñino. De tot això, la majoria no en sabíem gran cosa, però potser sí que en quedava l'atenció al detall, a la coma ben posada, el respecte per un text ben llegit. Aquest detallisme és una constant també en els millors treballs de la seva dedicació com a crític de poesia medieval: ara una nova identificació (Guerau de Maçanet), ara el sentit d'una paraula (civilment en la poesia XI d'Ausiàs March), i sempre la puntuació.

Josep Romeu va deixar estudis i edicions de relleu en diversos camps: entre els més destacats, la història del teatre català de tradició medieval, la vida i l'obra de Pere Serafí, la tradició folklòrica, la poesia popular i la seva influència en la culta del segle XVI ençà —amb especial referència al neopopularisme del seu admirat Bartomeu Rosselló-Pòrcel-, i la versificació. En ingressar a la Reial Acadèmia de Bones Lletres el 1972, va llegir un discurs sobre Joan Timoneda i el Cancionero llamado Flor de enamorados, contestat pel seu mestre Jordi Rubió i Balaguer, que acabava citant-ne una corranda: «quant més leal vull ser, / més se dobla lo meu mal». Poc després va publicar al Boletín de l'Acadèmia (1975-1976) un article sobre tot Pere Serafí. Són dues peces acadèmiques admirables. El mateix Romeu va aprofitar la segona en editar les Poesies catalanes de Serafí (2001), però encara avui ofereix molts motius de represa als estudiosos de les literatures hispàniques $\mathrm{i}$ als qui s'interessin pel Renaixement des de qualsevol camp.
Ja jubilat, mentre apareixien seguit seguit les recopilacions, les insistències $i$ els excursos, $i$ els panegírics, Josep Romeu va anar tornant a la pràctica de la poesia que havia abandonat a les acaballes dels anys cinquanta. No sobtava del tot, perquè havia exercit de crític militant de poesia des dels temps clandestins d'Ariel, i havia mantingut l'ofici a propòsit d'obres estimades, com ara les de Joan Maragall, J. V. Foix, Jaume Agelet i Garriga o Joan Brossa (en aquest cas, després que Brossa hagués descobert l'exercici de la sextina a partir d'un article erudit de Romeu!). Però igualment sorprenia a alguns antics alumnes que només l'havíem conegut com a historiador de la literatura. «Què fa» — pensàvem - «retardant l'edició de Pere Serafí?». Ens estranyava que la represa poètica interferís en la dedicació filològica. Amb més anys a sobre, però, ens vam acabar adonant que tot plegat responia al mateix interès: formes diverses de dedicació a la poesia i una bona dosi de passió.

A Josep Romeu li agradava explicar anècdotes personals a casa seva, ja al passeig de Sant Joan, acompanyades amb l'efecte de la pipa que atenua el somriure. Entre les més antigues, hi havia la de l'escola de petit, seguidora del sistema Montessori, quan se les havia enginyat per fer una maqueta que separava físicament Catalunya de la resta de l'Estat, com si fos un cantó de Suïssa. I la de quan havia desarmat un policia a la Universitat Autònoma de preguerra. Aquestes anècdotes, l'ambient de les quals es pot entendre llegint el principi del seu Quadern de memòries (2003), demostren la passió juvenil, per no dir la febrada. La mateixa passió devia córrer per sota d'una dedicació poètica estroncada i represa molts anys després. La mateixa, en certa manera, devia vessar-se - desviar-se- quan posava la coma al lloc que creia més adequat, quan precisava el sentit d'una paraula o una expressió, quan volia entendre humanament uns versos, fossin de Pere Alemany o de Jordi de Sant Jordi o d'un contemporani. A alguns dels seus antics estudiants, crescuts d'una manera diversa, ens va quedar l'exemple de la passió domesticada, una mena de filologia sempre amatent al valor del vers.

Lluís CABRÉ 